\title{
The Pedagogical Challenges of Creating Information Literate Librarians
}

\author{
Maryam Derakhshan ${ }^{1}$, Mohammad Hassanzadeh ${ }^{2}$, Susan E. Higgins ${ }^{3}$, and Sara Abbaspour Asadollah ${ }^{4}$ \\ ${ }^{1}$ Department of Library \& Information Science, \\ University of Malaya, 50603 Kuala Lumpur, Malaysia \\ e-mail: derakhshan1369@yahoo.com \\ ${ }^{2}$ Assistant Professor, Department of knowledge \& Information Science, \\ University of Tarbiat Modares, Iran \\ e-mail: hasanzadeh@modares.ac.ir \\ ${ }^{3}$ Part-time Faculty, School of Information, College of Social and Behavioral \\ Sciences, University of Arizona, \\ Tucson, Arizona, USA \\ e-mail: higginss@email.arizona.edu \\ ${ }^{4}$ Doctoral Student, University of Mälardalen, Västeras, Sweden \\ e-mail: sara.abbaspour@mdh.se
}

\section{ABSTRACT}

The central role of library professionals is to help others find the information they need. Therefore, LIS academics equip themselves with the necessary competencies to access and communicate the required information in order to help students become information literate. The foundations for these competencies are instilled during the library and information science (LIS) program. This study investigated the challenges of developing an information literacy (IL) culture among LIS students in Iran. Taking an exploratory approach, the study used semistructured interviews to gather the data. Using the 2000 ACRL standards as a framework, the fieldwork questions were designed around the five areas of IL competencies. A total of 15 academics teaching 18 different LIS courses from six universities were interviewed. They were asked the challenges they faced in teaching these competencies, and the approaches they took or suggested in overcoming the challenge(s). A thematic approach was used to analyze the data. Some of the challenges for students mentioned by the interviewees were ambiguity about the discipline, inability to match subject relevance with appropriate sources of information, and lack of familiarity with databases. The results of this study contribute to our understanding of challenges in teaching IL in the LIS discipline, an area that has not been researched directly. New perspectives emerged from study. 
Keywords: Information literacy; Library and Information Science education; Information literacy pedagogy; Undergraduates, Iran, Higher Education.

\section{INTRODUCTION}

The importance of information literacy in any LIS program is evident and for this reason, IL is gaining a very high profile within LIS education. Librarians have to be fully aware of the importance of IL as a concept, understand its relevance in contemporary societies and learn about the main aspects of teaching IL (Igun \& Odafe, 2014; Grgić \& Špiranec, 2013).Librarians as educators have a crucial role to play towards promoting, developing and inculcating IL skills among students (Whitworth, 2011; Maitaouthong et al., 2012; Evans \& Saponaro, 2012).

LIS students need to obtain information skills during every phase of their education to enable them to act as providers of information literacy (Grgić and Špiranec, 2013; Becnel, et al., 2014). In order to fulfill this role, they should have an appropriate education themselves. In Iran, as a developing country, IL has not been considered or implemented seriously yet. For most students at higher education institutions in Iran, IL knowledge and skills are very important as most of them give evidence of deficiencies in terms of their information skills. It is not only the lack of planning and strategy for the delivery of information literacy, the use to a lack of infrastructure and proper access to information is a countrywide issue.

Using data from a study conducted in 2014 in six Iranian universities, this article describes the challenges which educators face in employing the module outlines and curriculum to teach information literacy to undergraduates LIS students. It is clear that potential opportunities need to be considered by LIS program in Iranian universities, and the challenges facing LIS educators in 
teaching IL as well as the approaches in developing IL competencies in LIS students need be explored.

\section{IL Context and Background}

A fundamental issue among information users is acquisition of adequate skills and knowledge (Machin-Mastromatteo, 2015) as it is very competitive for information users to be able to use information in the Global Information Age. Information literacy creates awareness among individuals in terms of information practices effective in all aspects of life such as personal, political and business life. According to Limberg et al., (2013) “information literacy can be approached as an object of teaching as well as an object of learning". Information literacy is both a common and an important learning activity within higher education (Budd et al., 2014; Frank \& MacDonald, 2016). Such knowledge and skills for the majority of Students enroll at universities without knowing enough about basic library use and searching information skills, as well as information skills in general in a conceptual sense. The library infrastructures in Iran are inadequate; students are educated without adequate learning facilities. This situation is reported by several articles including Amiri (2010) and Davarpanah, Siamak and Ghassemi (2010). Derakhshan et al., (2014). Subsequently, little has Real Life experiences must be examined.

In Iran, the problem was clearly caused by the lack of familiarity with information literacy as a concept. Subsequenly, it was also clear that teaching approaches were required in order to equip Iranian students with IL skills and knowledge for their future lifelong learning skills. The challenges facing educators in Iran, particularly the information professional, remained to put into practice effective approaches that would achieve information literacy competencies among students required in the information age 


\section{LIS Education in Iran}

A review of LIS education in Iran indicates that formal training and education started in 1954. With the establishment of the first university in 1943, the University of Tehran, the first academic library was founded and an urgent demand for librarians was created. In the autumn of 1966, the Library Science Department was established in the Faculty of Education (Hayati \& Fattahi, 2005). After the revolution of the Islamic Republic in 1976, the curricula were restructured and LIS departments increased from 7 to 20. The number of universities offering LIS programs increased dramatically from 1997 until 2011 to keep LIS education at the forefront for strategic reasons. In 2005, some governmental universities established $\mathrm{PhD}$ programs to develop research programs.

LIS modules and curricula at the undergraduate level have been scheduled on the foundational basis that it generally takes four years to complete bachelor degree and award students with a certificate. The Bachelor program includes LIS subjects, as well as other basic and specialized optional courses on LIS. The Bachelor of LIS degree consists of 132 credits and normally can be taken in eight semesters.

\section{Information Literacy Education in Iranian Universities}

Using IL as a strategy for teaching and learning has been in place in Iranian educational institutions since 2006 (Fatemi, 2010). Various rubrics including hands-on practice, stand-alone lectures and orientation programs offer instruction to students on how to use information and find the information they need. Because attending these sessions is on a voluntary basis, occasionally academics request librarians to give instruction on a particular aspect of 
information. However, information literacy instruction was still confined to tours and bibliographic instruction then, which is a far cry from digital literacies (Fatemi, 2010).

In general, current IL instruction in Iran is weak in terms of its effectiveness in imparting IL competency skills and knowledge (Yari, 2012). The following reasons lead to this ineffectiveness:

- there is no IL training for instructors to equip them with certain skills;

- not all students are motivated to attend the sessions;

- information skills sessions are not linked to course offerings;

As observed by Derakhshan et al. (2014) the issue of IL not being integrated into regular courses or curriculum clearly compromises its effectiveness. In the current study, for example, the majority of educators confirmed the ineffectiveness of IL instruction being given.

\section{RESEARCH METHODOLOGY}

This study sought to explore the challenges of teaching IL in the context of undergraduate LIS programs in Iran. It took an exploratory case study approach as the nature of the data was qualitative.

A case study is considered as an empirical research that investigates a phenomenon within its real-life context (Yin, 2009), and in which the investigator aims to provide an in-depth description and analysis of the case (Creswell, 2013). It was identified as appropriate for this study as it aimed to explore the challenges of teaching IL in some real LIS programs to the development IL competencies in LIS students. As discussed below, findings emerged from interviews with LIS educators and the challenges they face in teaching of 18 LIS modules. They 
were asked to reflect on their teaching experience and explain whether and how they engaged students in developing the IL competencies. Then, they were asked about the challenges they faced in doing this.

The analysis reported in this article is of data collected as part of a wider exploratory study; in this article the following research questions were answered of participants:

- What challenges do LIS academics face to support the development of the five main areas of IL competencies among the LIS students, as future librarians?

- What are the approaches used by the academics to overcome these challenges?

\subsection{Selection of Cases for Study}

Six LIS undergraduate programs were selected in this study; these were taught by departments in governmental universities which were pioneers in LIS education. The teaching experiences of IL were identified as key constructs for this study. This guided the researcher to adopt an embedded single case study design as this study's focus on two units of analysis in the context of a single case (Yin, 2009). This design helped the researcher explore a wide range of challenges that educators face in teaching IL in the program.

\subsection{Selection of Key Informants}

Fifteen educators were interviewed in this study. Two main criteria were used to select these key informants: a) accessibility to the educators and; b) modules with different orientations or subject areas. This included 15 LIS educators who had experience teaching 18 modules in six different universities. The diversity in the educators' educational and 
professional backgrounds resulted in rich data. The researcher was provided with a dataset through a wide range of perspectives on challenges in teaching IL.

\subsection{Crafting Data Collection Instruments}

Semi-structured interviews were used to explore the phenomena under study that academics face in teaching IL. The researcher used a scenario-based interview approach, trying to situate the interviewees in some sort of scenarios and prompting them to talk about their experiences in particular modules which they were teaching In order to guide the interview and explore the subject of IL in LIS, the ACRL standards competencies were used to divide the interview questions into five areas. The interviews averaged 1 hour and 30 minutes in length. The following questions were asked:

- In which module are students expected to do a project assignment?

- What challenges do you face in teaching them to define their project assignment?

- What challenges do you face in helping them or supporting them to develop their topic?

- What approaches do you take or suggest overcoming these challenges?

The participants were asked to focus on their teaching experiences of LIS, and within that context they were asked to reflect on the challenges they face in teaching these competencies. To answer to these questions, the LIS academics were asked to think of a specific course they teach and reflect upon their experiences. As a result, a wide range of challenges in teaching IL competencies emerged as qualitative research data. 


\subsection{Data Analysis}

A grounded approach was taken to analyze the data in this study. Three phases recommended by Glaser and Strauss (1967), were followed to analyze the data:

a) the data was codified in the form of some themes for each area of IL competencies;

b) some memos reflecting the researcher's interpretation to each code were added;

c) Using evidence for each group of teaching experiences and challenges in each area of IL competencies, a narration for each of them was written.

Data collection and analysis was done simultaneously. This deepened the researcher's insights into the phenomenon under study (Eisenhardt, 1989). Due to the embedded design of the study, the challenges to teaching IL emerged from different perspectives as they were obtained from a wide range of units of analysis. In other words, first each unit was explored to identify statement(s) which represented each competency, then the data gained from different units was compared in a cross-search pattern. The researcher focused on the data from interviews in the five areas of IL competencies as follows:

- Challenges in teaching determining information need

- Challenges in teaching searching and locating for information

- Challenges in teaching evaluating information

- Challenges in teaching using information ethically

- Challenges in teaching using information for specific purpose

\section{FINDINGS}

Educators faced more challenges in teaching the first area of IL competencies which is “determining information needs". 


\subsection{Challenges and Approaches in Teaching Competency in "Determining Information Needs”}

The study identified a lack of understanding of LIS (as a discipline) as one of the barriers that affect effective implementation of this competency. Because such lack of awareness impacts the academic abilities of students, it creates disappointment and stress. Students think librarianship is merely about dealing with keeping books in a library and providing them for people who visit the library and do not see the profession as dynamic. Thus, librarians are seen as gatekeepers of information. In general, students' perception of LIS has been affected by beliefs about library and library materials. Most of them are not optimistic about making LIS as a profession and just want to pass the modules and obtain a university degree. "They are not familiar with LIS as a discipline and also its services and this causes disappointment and anxiety which in a way makes them unable to identify their information needs".

It is recommended that educators should change students' perception of LIS through connecting them with LIS activities; illustrating social aspects of LIS profession and assist them to obtain employment in order to overcome challenges in developing this competency.

The gap between the way of learning in schools and what is expected for students to perform at the university level emerged as another challenge. The 'teach to test' model of learning used in most schools has often been criticized. This lack of ability in defining information needs may be because of the old educational system which is 'content-based' rather than process based. 
“...Students have to memorize the subject materials and sit for exam to get a high score. They graduate from school with this approach which makes it difficult to help them to define their information needs.”

The importance of having the proper teaching style and traditional methods of delivery in order to effectively develop IL competencies has been stressed by Whitworth (2012). In the present study, educators do not follow the same way or same approach each time they teach. Some of the educators tend to act more passively, rather than using innovative approaches to engage students in defining information needs. Basically, they use a module outline to teach. Not all educators are creative and make the curriculum more up-to-date for the students. .. There is a need to use more up-to-date teaching approaches.

Teaching methods and styles were identified as a challenge for effectively addressing the concept of the user and his or her information needs.

"You know, the more I think about it...in my head, I am criticizing those students for not doing it [defining their information needs], but maybe it is not a fair criticism because some educators do not apply appropriate teaching methods to involve students in defining their information needs.

There is a need to shift from traditional view of teaching as content-based and teach to test to inquiry-based teaching, problem solving, research-based teaching, and 'Journal Clubs'. However, engaging students in Journal Clubs instead of relying on text books might be an effective way to develop ideas for their research projects. For example, students could find a paper in their subject area of interest and email it to their classmates, and then make a discussion in the form of presentation. 
Another challenge to emerge from the interviews with educators was the fixed nature of the LIS education system. This view was expressed particularly by some educators, whose enthusiasm for developing this skill can be attributed to the lack of flexibility within the LIS education system. "We (educators) are restricted to the module outline and don't have enough authority to do a number of changes in terms going further than module outline to involve students with defining their information needs."

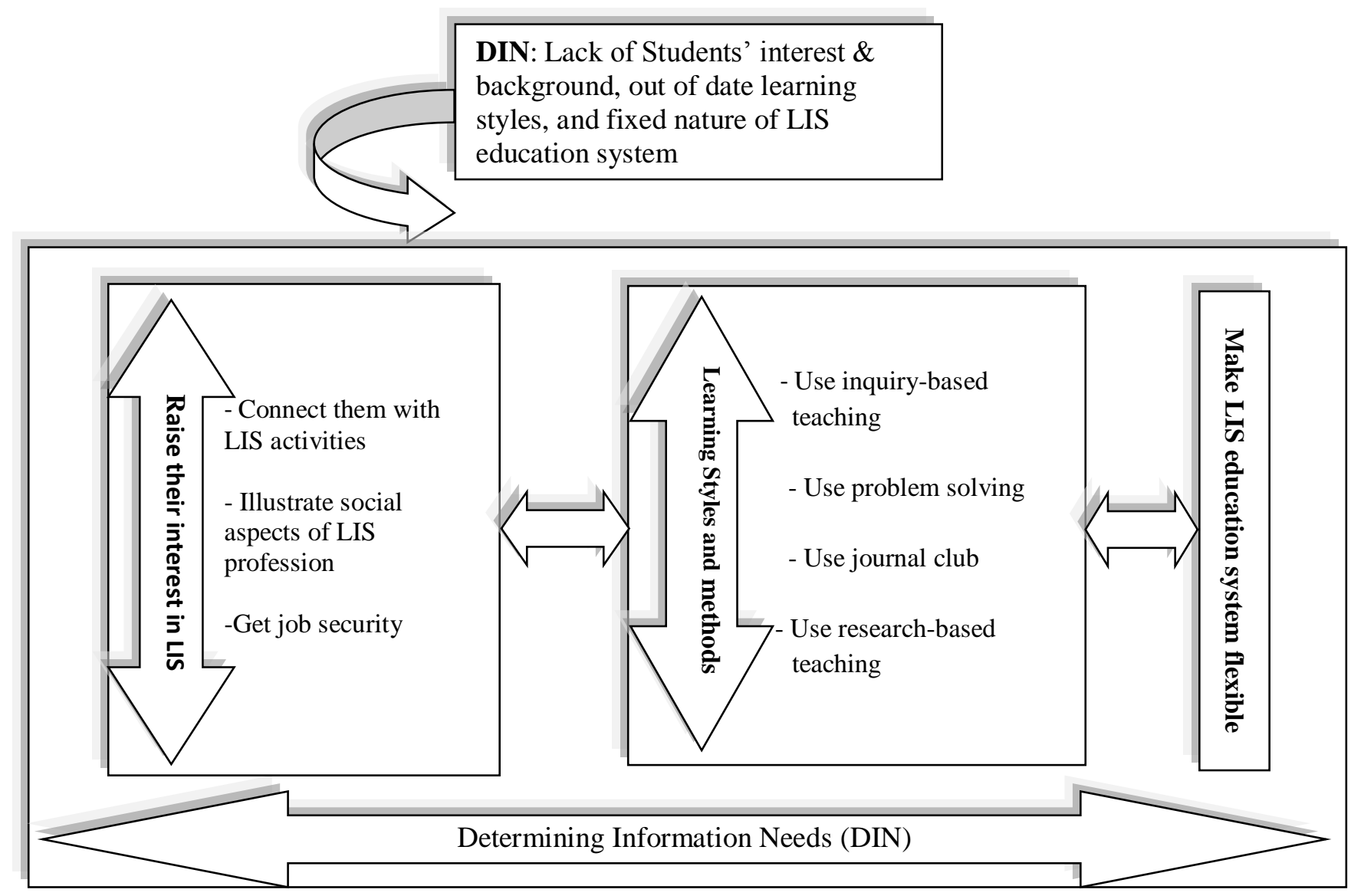

Figure 1: Challenges in teaching "Determining Information Needs (DIN)" 


\subsection{Challenges and Approaches in Teaching Competency in "Locating Information"}

Many of the educators interviewed acknowledged that students are not able to match subject relevance with sources. They stated that students do a search on the topic, then go through the results and if some results are not related, they ignore these. However, the strength of matching subject relevance with sources lies in students' knowledge of the topic area as well as reference sources:

"students just start looking for materials that refer to those words listed in the topic, because they don't know their topic area well, as an example; their topic is 'social media', they just look for that and don't know 'face book' is part or subcategory of social media'.

Connecting students with reference sources to find appropriate information could be effective in locating their information. This belief points to an assumption that 'Article Indexes' can be a good example of reference sources which lead to primary sources.

A perceived lack of IT literacy among students is another problem that affects locating information. While instructional opportunities on technology may exist, if students are not attending classes regularly, success will be limited.

The low level of interaction with databases appeared to be another challenge in locating information in students. While the databases are considered as important sources of information, most of the students do not know databases related to their discipline. Some of the educators believe that the lack of skill in locating information may be because of students' unfamiliarity with databases which focused on their discipline. The idea of running workshops on introducing different information databases to students was suggested to overcome this challenge. 
Lack of individual responsibility in locating information is viewed by educators as a striking challenge. In particular, personal interest in the subject area is considered as a critical determinant in locating information: "I think students can find any information if they have individual responsibility. 'Web' is a good source that students can go through that and find any information that they need". In their view the problem was that many students were not sufficiently enthusiastic in locating information.

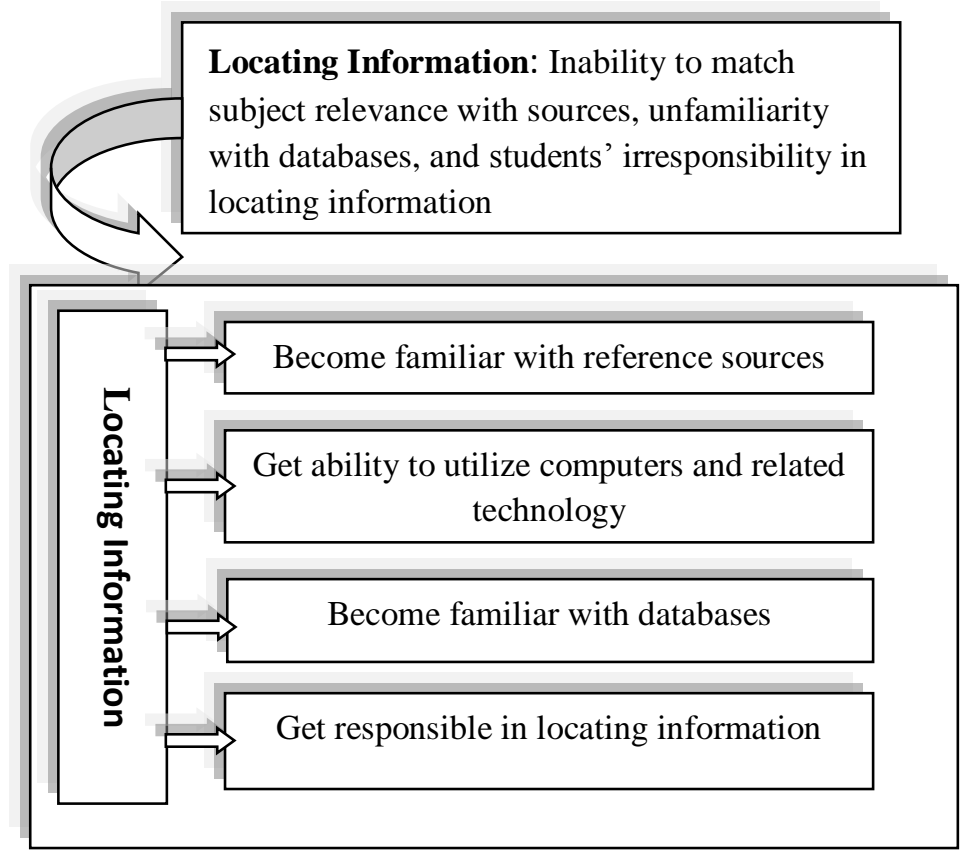

Figure 2: Challenges in teaching "Locating Information" 


\subsection{Challenges and Approaches in Teaching Competency in "Evaluating Information"}

One of the more obvious challenges to developing the evaluation skill was the belief that the extent to which students equipped with this skill depends almost on the module outline, rather than on the quality of the instructions which are available to explain the module. Thus, failure to evaluate information is viewed as a consequence of outdated module outlines. Students can obtain the evaluation skill if they put it into practice during the course of their education: "Well, I think if they are not able to evaluate the information and sources, it is because the module outline is out-dated, therefore the instructional opportunities don't work". The lack of evaluation skills on the part of students has made it remain an undiscovered competency for some educators. Educators' own understanding of evaluation skills presented as a learning curve for developing this skill in students: “...Well, not all the educators are equipped to evaluation skill. I believe that some of them do more 'copying and pasting' rather than evaluate information and its sources critically." To empower educators to overcome such challenges, there is a need for re-training sessions LIS educators.

The data analysis indicated that not all educators expect students to evaluate information and its sources. However, the key aspect of this belief was that undergraduate students do not require evaluating information and its sources. They are just expected to successfully complete the project and have no need to go through each process of information literacy in order to produce a particular end result.

The consequence of this belief is that the evaluation skill has not yet become a priority for all educators: "What is important for me in undergraduate level is methodology. I just want them to get familiar with the process of doing project as part of the module. I don't care whether they 
have got the main idea from information gathered or not." However, evaluating information is an interpretive skill which helps students develop this competency.

Developing the evaluation of information skill among students depends on students' own motivations and interests: "I think if they are not able to evaluate information, it is because they did not get motivation and interest to evaluate information." Failure to evaluate information is viewed as a function of students' personal motivation and interest on developing his/her evaluation skill. The idea of motivation and interest to obtain this skill is viewed as a strong indicator. "Well, they have facilities, internet connection with high speed; but they don't want to get the competencies including evaluating information, what students want is to complete their research paper or assignments in a way to satisfy their educator. I can teach them but I can't make them to learn."

Students are not able to make the connection between concepts and recognize the interrelationships among the concepts to incorporate information into their knowledge base: "...the most important problem that makes it difficult for students to evaluate information is that students' ability in recognizing the relationship between concepts and combine them into their knowledge base. In order to evaluate information should be able to find different aspects of a concept and find the similarities with other concepts and come up with a useful primary statement." If students would read their subject materials, this would help them to learn concepts, make connections between concepts and then combine them into their own knowledge base. 


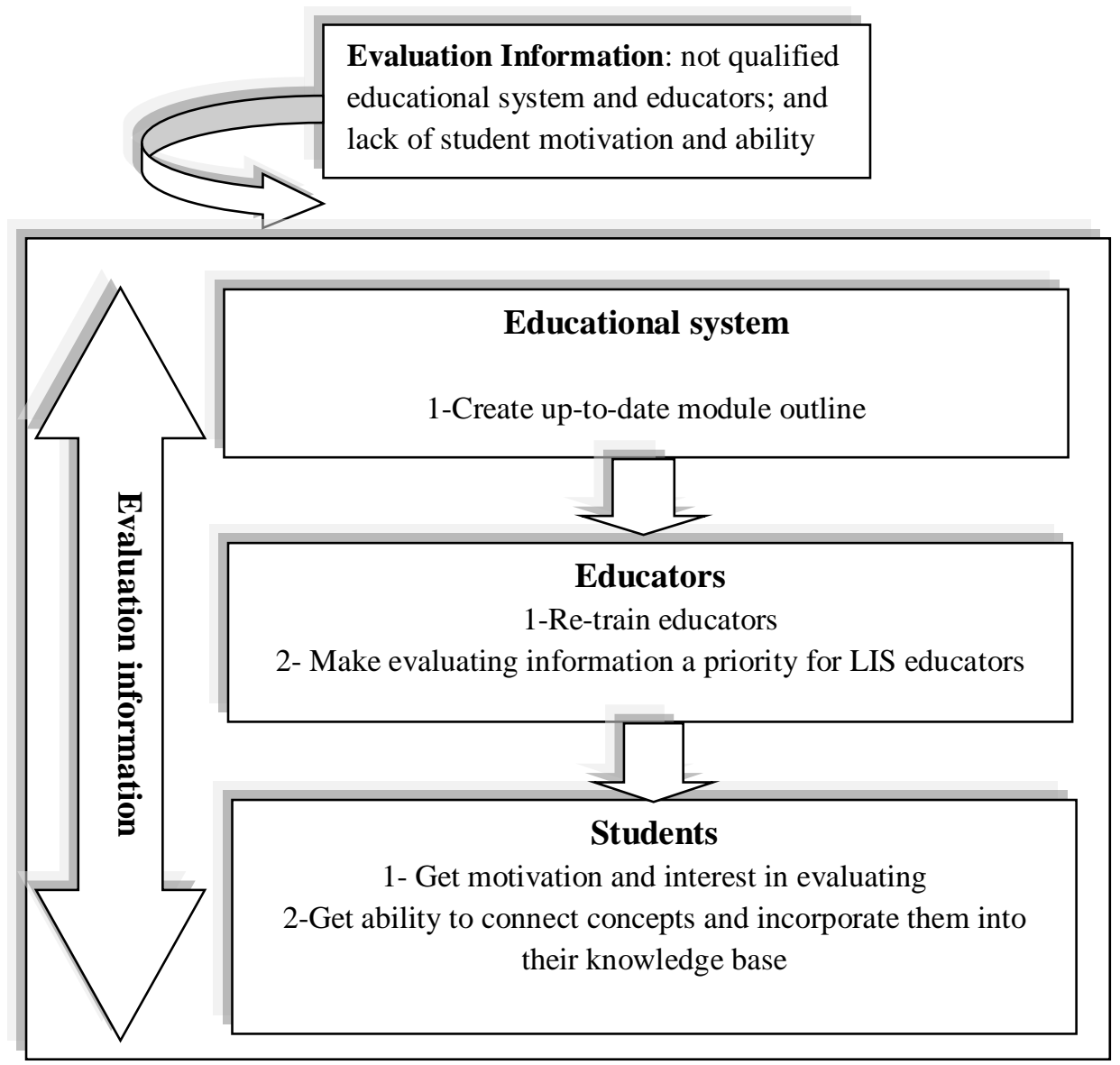

Figure 3: Challenges in teaching "Evaluating Information"

\subsection{Challenges and Approaches in Teaching "Using Information Ethically"}

Lack of students' familiarity with using information legally and ethically emerged as a negative influence on educators' approach to pedagogy: "unfortunately, they are not familiar with ethical use of information in both the print and electronic environment and they are not trying to do so". This makes educators to consider the belief that students 'intrinsic motivation' should be constructed to engage students to obtain information legally. Thus, educators expect students to understand the issues which related to copyright and fair use of information: "Students are not familiar with ethical use of information and more often do plagiarism." 
Undergraduate university students come from many types of families, with different cultures that makes it difficult for some of them to understand legal issues surrounding the use of information. They argue that the lack of understanding legal use of information to family culture and pre-university education suggests that students should get familiar with the ethical use of information use in school.

Another challenge emerged from the data analysis was that students do not have an ID and password to obtain information legally. It is apparent that it is challenging to get approved password and other forms of ID for access to information. One the ethical use of information is understood, students should be provided with password and ID to access to information. This access helps them to obtain, store and disseminate the needed information legally:

“...however, students are not able to obtain information legally and I think this is because they don't have password and forms of ID to get information." Students need be provided with approved passwords and other forms of ID for access to information 




Figure 4: Challenges in teaching "Using Information Ethically"

\subsection{Challenges and Approaches in Teaching Competency in "Using Information for a}

\section{Specific Purpose”}

Data analysis revealed that educators link the problem of a poor submission rate of short papers or minor essays to the students' reluctance to use information for a specific purpose. "Well, undergraduate students are reluctant to submit or publish a short paper and they just use information to satisfy their lecturer to get a mark. This attitude has a direct link with educational system which just encourages students to obtain a passing score. It follows that students should be encouraged to use information to write short papers and be provided with some guidelines.

The educators' belief that students come to use information for specific purpose through paraphrasing, centers on the concept of "putting into practice" which is predicated on the notion of providing students some opportunities to learn how to paraphrase. However, the data analysis shows that majority of students were not able to integrate new information with the prior one 
and make quotations or paraphrase them in a manner that supports the purpose of the product: "It is challenging for students to paraphrase the texts to support the storyline. They just try to pick the texts from different sources and then match it with each other, while they should manipulate the texts, transfer them into the new context, and create coherency to support the purpose of the essay or what else." As part of university policies, universities need to publish handbooks which cover how to paraphrase, and use quotations. Paraphrasing and using quotations effectively are the competencies that have been identified for LIS students.

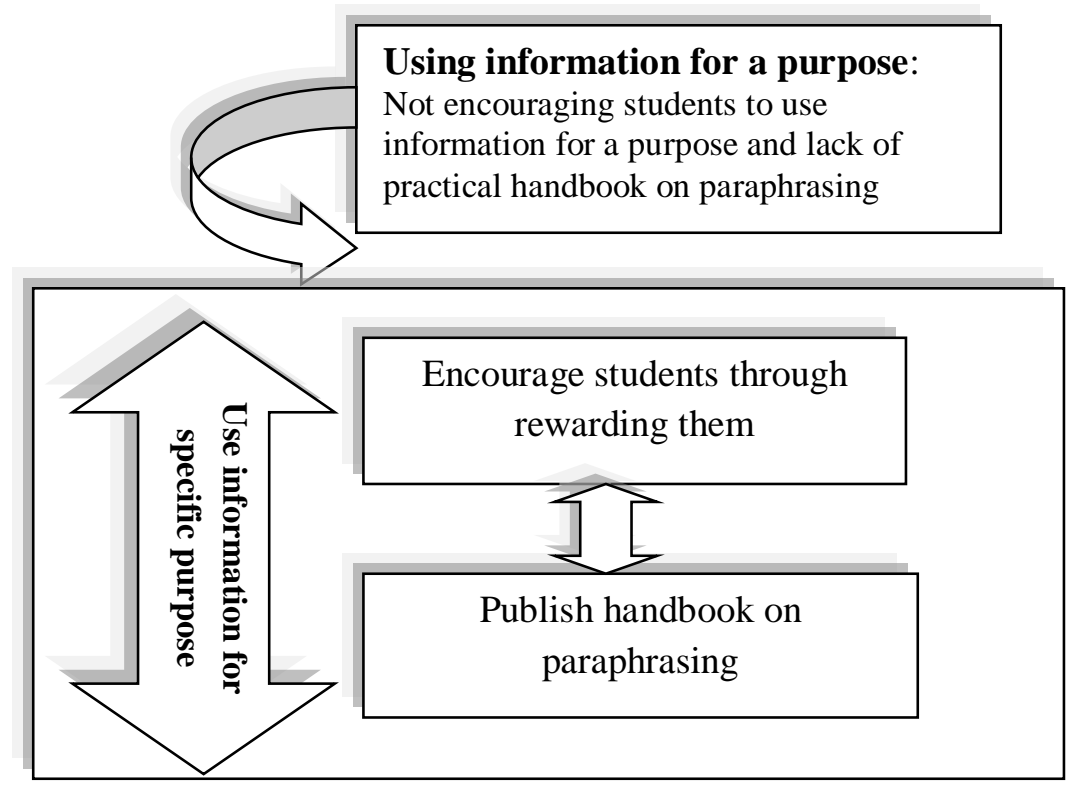

Figure 5: Challenges in teaching "Using Information for Specific Purpose"

\section{DISCUSSION}

IL is an essential competence for the LIS students. Its contribution in formal education is widely recognized, but it is now also acknowledged as a vital ability for LIS students in contemporary information-rich organizations. The present study investigated the challenges of developing IL competencies in LIS students by examining the challenges that LIS educators face in teaching IL in six universities and exploring the approaches to overcome the challenges. 
Literature on LIS students' information literacy status indicates that there is an insistent information literacy problem amongst the students. Some of the challenges on information literacy skills were due to four factors; lack of a solid information literacy program, lack of IT facilities, lack of proper planning or implementation and lack of support for the programs. These four factors can be summed up as a policy issue related to the integration of IL skills into the curriculum Rodríguez et al., (2015) points out that curriculum integration of IL is rooted in such factors. According to Fatemi (2010) a different set of information literacy problems occurred during the bibliographic instruction era. The lack of skills was still reported and the advent of Information Technologies (ITs) further complicated the type of skills needed by librarians. The ITs required appropriate facilities, proper planning and support from the librarians; therefore the information literacy problem had become much more complicated since the librarians also needed to have been trained to give the IT support needed. This problem as Abdi and Bruce (2015) mention, is that university policy on information literacy is constantly being reinvented.

Clearly there has to be an overarching reason for the apparent lack of IL skills reported in the literature. To understand the root cause of this phenomenon, it is important to revisit the conclusions made about IL skills (Rasoulabadi, 2010; Lysiak 2013) in order to understand the status of information literacy of students in higher education.

As mentioned in this paper, information literacy is a worldwide problem which needs a concerted effort to combat it. Ford \& Hibberd (2012) emphasized the self-perceived learning may be a potential barrier to student engagement with IL skills. Researchers have written about this phenomenon and they have concluded that information literacy is not just a set of short term tasks or list of skills to accomplish; it is made up of a broad spectrum 
of contexts (Forster, 2015; Howard, 2012). Some authors also noted that there is a lack of planning to information literacy programs (Beetham et al., 2009; Carncross, 2015). Other researchers maintain that technology is the root cause of failure to master IL skills. Still more researchers think that "a more radical challenge to IL practices is underway (Beetham et al., 2009).

The results showed variety in the challenges in teaching IL, which reflected themes in the literature which affect the development of IL. Almost all LIS programs lacked an IL policy coupled with the need for adequate training into disciplinary activity, although some IL rubrics were being practiced in some disciplines. IL development in LIS discipline has received less attention in the literature (Blumer et al., 2013), but could be connected with a recent Iran initiative to develop IL skills in some disciplines.

\section{CONCLUSION}

Overall, the study managed to address the challenges and approaches to overcome the challenges to the development of IL competencies among undergraduate LIS students. The results presented in this article show that it is important to take purposeful efforts to overcome the challenges in teaching IL to develop information literate students as future librarians. As Virkus (2007) notes teaching information literacy to LIS students requires an extensive knowledge of pedagogies.

A number of challenges have been discussed, and placed on a continuum which reflects the range of barriers in developing IL skills. The findings reveal that LIS students do not have a clear understanding of LIS and, consequently, they are not connected with LIS activities. Connecting them with LIS activities; illustrating social aspects of LIS profession, and obtaining 
job security are approaches that have been recommended by educators to overcome this challenge. Additionally, educators must revise the notion that learning to be information literate means shifting from teacher-centered teaching to student-centered learning (Maybee, 2015). They need to develop a critical consciousness about involving students with information, by supporting "problem-based" learning (Dash, 2015) or what Keene et al., (2010) calls "a problem solving education". With this shift, Library and Information Science (LIS) academics facilitate both LIS students' own learning in information literacy and these students' learning of how to facilitate others' information literacy (Virkus, 2007).

The notion of re-training educators featured strongly in educators' comments to overcome the challenges in teaching IL skills. In order to meet these challenges, educators should spearhead the potential opportunities in their institutions to make sure that IL is integrated into the LIS curriculum. The effectiveness of IL instruction is tackled through the establishment of strong links and partnerships within and across the educational system and teaching staff.

Having identified the importance of addressing challenges, the current study suggests a number of approaches to overcome the challenges to develop IL competencies in LIS students:

- To change students' way of viewing a problem;

- To acquire the knowledge needed in finding information;

- To obtain the skills needed in finding information;

- To make connections between concepts and their knowledge base;

- To identify ethical use information behavior;

- To gain the needed knowledge on paraphrasing;

This study is limited to LIS academics; studying students' reflections can bring broader perspectives to IL education in LIS program. Due to the nature of the design of this study which 
is a single case study, the teaching experiences of IL are limited to the ones which emerged and were addressed in the context of the case. Although, the case selection was made in a way that can be representative of the "general" in the "particular" bounded system of the case (Stake, 1998), studying more cases could certainly have brought broader perspectives to IL which could have been to wider contexts. 


\section{REFERENCES}

Abdi, E. S., \& Bruce, C. (2015), From Workplace to Profession: New Focus for the Information Literacy Discourse. In Information Literacy: Moving Toward Sustainability (pp. 59-69). Springer International Publishing.

Amiri, Z. (2010), "Surveying information literacy of higher education students in University of Shahr-e-Kord" Scientific Communication, Monthly Journal of Irandoc.

Becnel, K. E., Pope, J. C., and Moeller, R. A. (2014), Teaching and Learning Information Literacy: Embedded Library Science Students in Undergraduate English Courses.

Beetham, H., Lou McGill, A., Littlejohn, H. and Joint Information Systems Committee. (2009), "Thriving in the 21st century: Learning literacies for the digital age (LLiDA project)." [Accessed: October 10, 2014]

Blumer, E., Hügi, J., Bekavac, B., and Schneider, R. (2013), Information Literacy Competences of LIS-Students in Switzerland-a case study. In Worldwide Commonalities and Challenges in Information Literacy Research and Practice (pp. 596-602). Springer International Publishing.

Budd, J., Elmborg, J., Lloyd, A. and Sundin, O. (2014), "Theoretical Foundations for Information Literacy: A Plan for Action", In Annual Meeting of The Association for Information Science \& Technology. ASIS\&T.

Carncross, M. (2015), "Redeveloping a course with the Framework for Information Literacy for Higher Education", College \& Research Libraries News, Vol. 76 No.5, pp. 248-273.

Creswell, J. W. (2013), Research design: Qualitative, quantitative, and mixed methods approaches. Sage Publications, Incorporated.

Dash, A. R. (2015), Information literacy (IL) initiatives in Bangladesh: a case study (Doctoral dissertation, University of Dhaka).

Davarpanah, M., Siamak, M., and Ghassemi, A.H. "2010”, Measuring information literacy of students, Tehran: Dabizesh.

Derakhshan, M., and Singh, D. (2011), "Integration of information literacy into the curriculum: a meta-synthesis", Library Review, Vol. 60 No. 3, pp. 218-229.

Derakhshan, M., Singh, D., and Nazari, M. (2014), "The Contributions of Library and Information Science Education to the Development of Competencies in Determining Information Needs: An Iranian Case Study", Libri. International Journal of Libraries and Information Services, Vol. 64 No. 2, pp.144-154.

Eisenhardt, K.M. (1989), "Building theories from case study research", The Academy of Management Review, Vol. 14 No. 4, pp. 532-550.

Evans, G.E. and Saponaro, M.Z.,(2012), Collection management basics. ABC-CLIO.

Fatemi, O. (2010), Country Report on Information Access and Media and Information Literacy: IRAN. 5TH ASIA-PACIFIC INFORMATION NETWORK (APIN) MEETING and ICT LITERACY WORKSHOP 23-26 November 2010 • Manila, Philippines.

Ford, P. J., and Hibberd, K. (2012), "Creating effective and engaging information literacy programmes for the dental curriculum", European Journal of Dental Education, Vol. 16 No. 1, pp. e41-e46.

Forster, M. (2015), "Refining the definition of information literacy: the experience of contextual knowledge creation", Journal of Information Literacy, Vol.9 No. 1, pp. 62-73. 
Frank, E.P. and MacDonald, A.B., (2016), "Eyes Toward the Future: Framing For-credit Information Literacy Instruction" Codex: the Journal of the Louisiana Chapter of the ACRL, Vol. 4 No. 4, pp. 9-22.

Glaser, B., and Strauss, A. (1967), The discovery of the grounded theory: Strategies for qualitative research, New York: Aldine de Gruyter.

Grgić, I. H., and Špiranec, S. (2013), Information Literacy of LIS Students at the University of Zagreb: Pros or Just Average Millennials, In Worldwide Commonalities and Challenges in Information Literacy Research and Practice (pp. 580-587). Springer International Publishing.

Hayati, Z., \& Fattahi, R. (2005), "Education for librarianship in Iran before the 1979 Islamic Revolution: A historical review of American roles and influences", Library Review, Vol, 54 No.5, pp. 316-327.

Howard, H. (2012), "Looking to the future: Developing an academic skills strategy to ensure information literacy survives in a changing higher education world", Journal of information literacy, Vol, 6 No.1, pp. 72-81.

Igun, S. E., and Odafe, J. P. (2014), "Information Literacy Among Undergraduate Students in Nigeria", International Journal of Digital Literacy and Digital Competence (IJDLDC), Vol. 5 No. 3, pp. 1-14.

Keene, J., Colvin, J. and Sissons, J. (2010), "Mapping student information literacy activity against Bloom's Taxonomy of cognitive skills" Journal of information literacy, Vol, 4 No. 1, pp. 6-21.

Limberg, L., Sundin, O. and Talja, S. (2013), "Three theoretical perspectives on information literacy", Human IT: Journal for Information Technology Studies as a Human Science, Vol. 11 No. 2.

Lysiak, L. (2013), "Information Literacy Instruction That Works: A Guide to Teaching by Discipline and Student Population”, Library Collections, Acquisitions, and Technical Services, Vol. 37 No. 3-4, pp. 121-122.

Machin-Mastromatteo, J. D., and Lau, J. (2015), "The arrival of information literacy",Information Development, Vol. 31 No. 2, pp.190-193.

Maitaouthong, T., Tuamsuk, K., and Tachamanee, Y. (2012), "The roles of university libraries in supporting the integration of information literacy in the course instruction", Malaysian Journal of Library \& Information Science, Vol. 17 No. 1, pp. 51-64.

Maybee, C. (2015), "Preparing Today's Learners: The Role of Information Literacy in the Adoption of Innovative Pedagogies".

Rasoulabadi, M. (2010), "Surveying information literacy status of Medical students and their attitudes toward IT in the University of Kurdistan" Information Sciences \& Technology.

Rodríguez, K., Cádiz, L., and Penkova, S. (2015). "Integration of Information Literacy (IL) Skills into the Core Business Curriculum". In The Third European Conference on Information Literacy (ECIL) October 19-22, 2015, Tallinn, Estonia (p. 139).

Stake, R. E. (1998), Case studies. In N. K. Denzin, \& Y. S. Lincoln (Eds.), Strategies of qualitative inquiry (pp. 86-109). London: Sage.

Virkus, S. "2007”. "Information Literacy within LIS curriculum”. Available at: http://dspaceunipr.cilea.it/handle/1889/530 (accessed 10 July 2014).

Whitworth, A. (2011), "Empowerment or instrumental progressivism?: Analyzing information literacy policies", Library trends, Vol. 60 No. 2, pp. 312-337.

Whitworth, A. (2012), "The Reflective Information Literacy Educator", Nordic Journal of Information Literacy in Higher Education, Vol. 4 No. 1, pp. 38-55. 
Yari, S. (2012), "Information Literacy in Iran". Library and Information Science, Vol. 14 No.1.

Yin, R. K. (2009), Case study research: Design and methods (Vol. 5). Sage. 